\title{
Hsp70 function and polymorphism, its implications for mollusk aquaculture: a review
}

\author{
Adán Valenzuela-Castillo ${ }^{1}$, Arturo Sánchez-Paz ${ }^{2}$, Reina Castro-Longoria ${ }^{1}$ \\ Marco Antonio López-Torres ${ }^{1}$ \& José Manuel Grijalva-Chon ${ }^{1}$ \\ ${ }^{1}$ Departamento de Investigaciones Científicas y Tecnológicas, Universidad de Sonora \\ Hermosillo, Sonora, México \\ ${ }^{2}$ Centro de Investigaciones Biológicas del Noroeste S.C., Laboratorio de Referencia \\ Análisis y Diagnóstico en Sanidad Acuícola, Hermosillo, Sonora, México \\ Corresponding author: José Manuel Grijalva-Chon (manuel.grijalva@unison.mx)
}

\begin{abstract}
Hsp70 proteins are widely found through several species, and they are considered among the most conservative proteins in nature, in both their sequence and function. They play an important role in the response mechanism to several different kinds of stress such as temperature and pathogens among others. In some species, the variations in the sequence of the Hsp70 gene result in intra-specific differential expression, and therefore in differences in thermo-tolerance of individuals as well as other productive characteristics. The study of the potential impact of the Hsp70 gene polymorphisms represents a field of study that could greatly help the mollusk farming industry.
\end{abstract}

Keywords: bivalve mollusks; differential genetic expression; genetic polymorphism; heat-shock proteins; thermotolerance

\section{INTRODUCTION}

Shellfish culture is regarded as an important economic activity, but its production is affected by many factors, which include abrupt changes in temperature and exposure to pathogens, among others (Gosling, 2003). Examples of these are the organisms that live in the intertidal zone which are exposed to temperature fluctuations, especially in geographic areas with significant seasonal variations (Hamdoun et al., 2003). Prolonged exposure to environmentally induced conditions of heat stress significantly decreases the survival of organisms, which has economic implications for the worldwide aquaculture industry.

Extreme temperatures cause severe cell damage due to irreversible protein denaturation (Hamdoun et al., 2003; Li et al., 2007; Farcy et al., 2009). The mechanism of cellular stress response of different species of bivalves involves the rapid synthesis Hsp70 (Franzellitti \& Fabbri, 2005; Piano et al., 2005; Farcy et al., 2009; Yue et al., 2011), which aims to cellular protection by stabilizing proteins, denaturing process, and participating in processes of acquired resistance, including thermo-tolerance (Brun et al., 2009; Farcy et al., 2009; Jackson et al., 2011).

Recent reports have indicated an intraspecific differential expression of Hsp70 to thermal stimuli (Dong et al., 2010; Kang et al., 2011a; Kawabe \& Yokoyama, 2011), which has been associated with the existence of polymorphism in the gene Hsp70 of different species (Bernabucci et al., 2010; Li et al., 2010). It is known that the 3 '-end of the Hsp70 gene has a higher number of polymorphic sites (Ravaux et al., 2007; Bernabucci et al., 2010; Montero-Barrientos et al., 2010; Kang et al., 2011a; Li et al., 2011) which could be related to the intrinsic thermo-tolerance of each species as well as individuals.

Without a doubt, shellfish aquaculture and fisheries are of great economic importance, so the understanding of the molecular mechanisms that possess these species to respond to various environmental stimuli is important since such knowledge can be helpful to the industry. Moreover, by assessing individual responses to different environmental conditions the organisms

Corresponding editor: Erich Rudolph 
best adapted to the specific environmental characteristics of each region can be identified.

\section{Heat-shock proteins: features and general aspects}

It is now recognized that the tertiary and quaternary structures of the polypeptides give them their specific functionality (Nelson \& Cox, 2008). These structures may be affected by physical or chemical changes such as extreme temperature and $\mathrm{pH}$ that can induce cleavage of the polypeptide chain. The denatured proteins lose every biological functionality and may be irreversible if they form aggregates ( $\mathrm{Li}$ et al., 2007; Farcy et al., 2009; Konermann, 2012). The organisms have various mechanisms to mediate and repair damage caused by various cellular stressors. So, when organisms are under stress, in addition to presenting changes in their behavior, they promote the synthesis of various specialized proteins responsible for stabilizing and avoiding unfolding and subsequent aggregation of protein products.

Among the wide variety of proteins responsible for repairing the damage caused by numerous stressors, are the so-called heat-shock proteins (Hsp's), also considered within molecular chaperones (Pennarossa et al., 2012). These proteins were first reported by Tissieres et al. (1974) who by exposing larvae of Drosophila melanogaster to extreme temperature, observed different proteins in the salivary glands that were not present before the heat treatment. The Hsp's can be synthesized by most of the studied species, such as mammals (Basiricò et al., 2011; Li et al., 2011), insects (Zizzari \& Ellers, 2011; Calabria et al., 2012), fish (Hofmann et al., 2000; Narum \& Campbell, 2010; Dalvi et al., 2012; Liu et al., 2017), mollusks (Jackson et al., 2011; Zerebecki \& Sorte, 2011; Lim et al., 2012; Thompson et al., 2012; Brokordt et al., 2015) echinoderms (Dong et al., 2010) and crustaceans (Ravaux et al., 2007). In all these species groups, the heat-shock response is highly conserved, as is the sequence of the genes that control the mechanism (Kawabe \& Yokoyama, 2011; Park et al., 2012; Wojstasik \& Wisnik, 2012).

The Hsp's are classified based on their molecular weight; the most studied are those of the Hsp70 family. Other families of great importance are the Hsp40 and Hsp90, which together with Hsp70 are comprised of proteins with a molecular weight of about 40,70 and 90 $\mathrm{kDa}$ respectively. These proteins form a complex at a cytosolic level, along with a factor called heat-shock factor (HSF), when the cells are not in stress. The complex dissociates to start the heat-shock response when there are proteins in the denaturation process (Tomanek \& Somero, 2002).
There are two ways in which the Hsp's can be expressed: 1) constitutively, or 2) induced (Clark et al., 2008; Witt, 2010; Jackson et al., 2011). Hsp's are produced in response to acute cellular stress (Piano et al., 2002; Farcy et al., 2009; Li et al., 2011) produced by external stressors such as drastic temperature changes, amino acid analogues, heavy metals, free radicals, environmental contaminants, immune stimulants agents, inhibitors of metabolic energy and various diseases, among others (Hooper et al., 2012; Wei et al., 2012; Malyshev, 2013; Brokordt et al., 2015; Ravaschiere et al., 2017). Wang et al. (2006) observed an increased expression of Hsp70 and Hsp90 in Fenneropenaeus chinensis infected with White Spot Virus (WSSV), compared to healthy individuals, while Wei et al. (2012) detected an increased expression of Hsp70 in Miichtys miiuy infected with bacteria of the genus Vibrio. Furthermore, it has been suggested that Hsp's also have immune-regulatory functions due to their ability to participate as a pro-inflammatory agent, warning the immune system and triggering cytokine secretion.

Moreover, the constitutive heat-shock proteins are those expressed continuously and are involved in some mechanisms that aim to maintain homeostasis in different cells, as the active protein repair in the translation process, the protection of intracellular enzymes and hormone receptors, cytoskeletal repair, among others (Roberts et al., 2009). Hsp's are essential for many vital mechanisms for the different species. In this way, the study of its expression at the cellular level can help in understanding the response of an individual of a given species to various environmental stimuli. Therefore, the study of Hsp's is a potential tool for monitoring mollusk species of aquaculture interest.

\section{Heat-shock protein of $70 \mathrm{kDa}$}

The Hsp70 protein family is the most studied thermal shock proteins because they usually have a higher expression when an individual is subjected to situations that trigger a response mechanism to thermal shock as well as being one of the most highly conserved. Farcy et al. (2009) reported that under a thermal stress challenge, Crassostrea gigas had higher expression levels of Hsp70 compared with the expression of other genes related to cell stress. It has been suggested that Hsp70s have a direct relationship with the development of acquired thermo-tolerance, and once an organism has been exposed to a sub-lethal temperature, it acquires the ability to withstand higher temperatures than those considered within its normal range (Sung et al., 2011). According to Spriggs et al. (2010), this is due to the existence of a "cell reservoir" of Hsp70 previously synthesized within cells. In recent studies, Park et al. 
(2012) observed that when the putative mitochondrial form of Hsp70 from Porphyra seriata was introduced and overexpressed in cells of Chlamydomonas under heat stress conditions, the rate of growth and survival were higher than that observed in organisms from natural populations.

These proteins are found in the cytosol and organelles such as mitochondria, chloroplasts, endoplasmic reticulum and others (Roberts et al., 2010). Usually, they are related to the de novo protein folding, while under heat stress perform functions of containment and damage repair. These proteins have three domains, which together are called "ATPase cycle": The NATPase domain (NATPD) that hydrolyze ATP; the substrate recognition domain (SRD), which serves to anchor proteins; and the C-terminal domain (CTD) that provides a "cap" for the linker substrate domain. According to Richter et al. (2010), in addition to its activity, it is dependent on the ATP, and it is also regulated by the interaction with cofactors such as Hsp40/J Proteins family.

\section{Function under physiological conditions}

Under physiological conditions, Hsp70 together with other proteins responsible for assisting them, known as co-chaperones $(\mathrm{CoCH})$, has the function of keeping the protein homeostasis within the cell since it is not necessary to enter a condition of heat stress to expose the hydrophobic domains (Malyshev, 2013). During the translation process, there is an association of Hsp40 with hydrophobic areas of polypeptides synthesized on ribosomes, to subsequently attach them to SRD of Hsp70. In a final step, there is an increased affinity of the SRD to the hydrophobic portion of the polypeptide due to the ATP hydrolysis mediated by the interaction of Hsp70 with NATPD. At the same time, there is a conformational change in the CTD, such that protects the hydrophobic sites of the protein to stabilize (Malyshev, 2013).

In solution, with a $\mathrm{pH}$ close to neutral values, and without the presence of destabilizing agents and with moderate temperatures, most proteins form compact and highly ordered structures (Konermann, 2012). However, the intracellular conditions are entirely different since there are a lot of molecules capable of interacting with the unfolded protein. Once the protein is stabilized, the nucleotide exchange factor (NEF) promotes regeneration of ATP joined to NATPD, causing conformational changes in the SRD of Hsp70 and the releasing of the substrate. Therefore, the folding occurs after the substrate is released, thus preventing interactions before the synthesis and therefore avoiding the formation of aggregates (Malyshev, 2013; Willmund et al., 2013).
The Hsp70 and $\mathrm{CoCH}$ are involved in the folding mechanism of proteins and participate in the transport of proteins into organelles. In addition, the Hsp70, assisted by the proteins mentioned above, recognize irreversibly damaged proteins and then proceed the ubiquitination and the proteosomal degradation. Also, Hsp40 deliver target proteins to Hsp70 and stimulates the hydrolysis of ATP. Likewise, the Hsp70/Hsp90 complex, together with other $\mathrm{CoCH}$, recognizes the normal protein containing the tag sequence KFPRQ and sends it to lysosomes for degradation (Malyshev, 2013).

\section{The Hsp70 synthesis in response to heat stress}

Organisms must be able to adapt to environmental changes to survive. In the case of marine species, multiple factors are affecting the aquatic environment, for example, extreme temperatures, $\mathrm{pH}$ changes, exposure to pollutants, among others (Sung et al., 2011). It is considered that temperature is one of the most important factors because it has a great effect on various aspects, such as metabolic rate, growth, reproduction, and migration. For bivalve mollusks that live in the intertidal zone, the temperature is one of the most important factors (Samain, 2011).

Abrupt changes in thermal conditions can generate different types of damage to living organisms. The exposure of organisms to large temperature fluctuations outside the temperature range of tolerance is called heat-shock (Nollen \& Morimoto, 2002). In this way, when the body temperature of an organism exceeds the specific range required for normal metabolic activity, it results in an overall heat load that exceeds its ability to dissipate heat, which promotes the generation of physiological responses and behavior that are intended to reduce potential damage, according to Bernabucci et al. (2010) and Nollen \& Morimoto (2002), is called heat-shock response.

During periods of thermal stress, the metabolic rate of the organisms decreases, as a result of the rate of synthesis of constitutive proteins responsible for maintaining homeostasis in normal conditions also decreases; this may cause degradation of essential components for cell viability. According to Spriggs et al. (2010), this is due to the overall inhibition of protein synthesis or the suspension of the protein translation processes.

The response to heat-shock is characterized by the rapid synthesis of various proteins responsible for repairing damage at the cellular level, and in the absence or reduction of the constituent proteins responsible for maintaining homeostasis within cells. There are several proteins responsible for repairing this damage, such as heat-shock proteins (Hsp), metallothionein, glutathione S-transferase and superoxide 
dismutase (Farcy et al., 2009), which, when expressed under conditions of stress, are vital to the survival of organisms after being exposed to heat stress.

Major damage due to extreme temperatures is due to irreversible denaturation and subsequent protein aggregation. Usually, under non-stress conditions, the Hsp's form an inactive complex (HSCI) at a cytoplasmic level, formed by the monomer heat-shock factor (HSF), the Hsp90-p23-immunophilin complex, Hsp70, and Hsp40. However, the presence of proteins with exposed hydrophobic domains causes the HSCI dissociation, and the response to heat-shock begins (Malyshev, 2013) and initiates the synthesis of Hsp70.

Studies have shown that acclimation temperature has a direct effect on the threshold temperature for the induction of Hsp70 synthesis and the intensity of the response. Thus, the organisms present variations with respect to the expression of Hsp70 gene throughout the year depending on the average temperature at which they were exposed. Dalvi et al. (2012) found that in Horabragus brachysoma acclimated at different temperatures, they showed differences in the intensity of the response to heat stress, being much higher in organisms exposed to a higher temperature acclimation. Also, Farcy et al. (2009) reported variable expression levels of Hsp70 in Crassostrea gigas, along different seasons, however, they found no correlation between the intensity of the expression of this gene and magnitude of changes in surface temperature of the sea. In this sense, Liu et al. (2017) are concerned about ocean warming, resulting from global climate change, and its relationship with the ability to express Hsp70 and the thermal tolerance of demersal fish. On the other hand, Valenzuela-Castillo et al. (2015) proved that in cultures of $C$. gigas from areas with large seasonal temperature fluctuations and extreme tidal range, as in the middle and upper Gulf of California, the difference between seasonal expression levels of Hsp70 is great. Nevertheless, there is evidence that Hsp70 synthesis processes under thermal stress may be different among oysters, mussels, and clams (Sung et al., 2011).

\section{Hsp70 polymorphism}

The function of proteins depends on their amino acid sequence, and this in turn to the base sequence of the gene (Nelson \& Cox, 2008). Each species can synthesize many proteins with unique functions conferred by its native structure, which is given by the amino acid sequence of the protein itself (Nelson \& Cox, 2008). However, there are many polymorphic proteins that vary their amino acid sequence, in some cases, without affecting their activity (King, 2000) since there are amino acids that have similar properties among them (Swynghedauw, 1998). Genetic polymer- phism refers, therefore, to changes in the nucleotide sequence of a gene coding for a particular protein type and has a significant frequency along the population (King, 2000). In species of interest for aquaculture, many single nucleotide polymorphisms (SNPs) have been detected that are associated with important traits such as linkage maps, growth, morphological characters, sex determination, resistance to pathogens, responses to thermal stress and low oxygen tolerance, and traceability (Wenne, 2018).

It is now considered that the Hsp70 genes from different species are highly conserved. For example, the Hsp70 from Escherichia coli has about 50\% identity with those found in eukaryotic cells of higher organisms. Nonetheless, several research studies have found polymorphic sites in Hsp70. Narum \& Campbell (2010) found the existence of polymorphic sites in Hsp70 and Hsc71 in three species of Oncorhynchus (Salmonidae). Kang et al. (2011a) determined the existence of single polymorphism sites in the sea cucumber Apostichopus japonicus, while ValenzuelaMuñoz et al. (2013) reported the presence of polymorphic sites in the abalone Haliotis rufescens. Recently, Valenzuela-Castillo et al. (2015) reported several polymorphic sites in the 3'-end of Hsp70 of the Pacific oyster $C$. gigas.

Among individuals of the same species, there is a differential expression of Hsp70 to thermal stimuli (Tine et al., 2010), and this has been associated with the presence of polymorphic sites in the Hsp70 genes (Bernabucci et al., 2010; Li et al., 2011). In the sea cucumber Apostichopus japonicus of blue and red variants, Dong et al. (2010) reported a significant difference in the expression of Hsp70, whereas certain SNPs define the color of the organisms in this gene (Kang et al., 2011a). Basiricò et al. (2011) reported that in individuals of Italian Holstein dairy cattle, individuals who have certain genotypes of this gene had increased production of transcripts and this is related to a better response to thermal shocks. Other authors suggest that the mutations in the promoter region affect the positive regulation of this gene (Kresfelder et al., 2006). In addition to the modification of the protein structure, changes in the sequence of some areas of a gene may have different consequences. If the polymorphic sites are in cis-regulatory regions, then gene expression is directly affected (Narum \& Campbell, 2010). It has been found that variations in the 5'- or 3'-end modified the mRNA stability of the Hsp70 gene (Dong et al., 2010). Therefore, the presence of certain phenotypes would be an advantage for stress conditions on individuals carrying a particular genotype. 
In several species, there is a relationship between certain polymorphic sites in the sequences of different genes and their expression levels. In the case of Hsp70, Basiricò et al. (2011) found that the existence of variable sites located at bases 895 and 1128 of Italian Holstein cattle, is associated with overexpression of the gene.

It is considered that the N-ATPase dominium in Hsp70 is highly conserved across different taxa, while the other two domains have greater variability (Liu et al., 2010). It has been suggested that variations in the 3 '-end of Hsp70 may determine interspecific differences in thermotolerance as reported by Li et al. (2011) in Asian Holstein cattle. Differences in thermotolerance are due to differences in the sequence the Hsp70 gene; it is, therefore, plausible to consider that a broodstock could be selected with a specific genotype of Hsp70 associated with desirable characteristics in thermotolerance, and other good traits. However, studies are required to certify this gene as a quantitative locus associated with certain productive characteristics.

The evaluation of the presence of polymorphic sites in Hsp70 of shellfish of aquaculture interest has been carried out in very few species. Kang et al. (2011b) analyzed the phylogeny of seven species of abalone, and Valenzuela-Muñoz et al. (2013) reported several polymorphic sites in $H$. rufescens. Valenzuela-Castillo et al. (2015) found several polymorphic sites in the 3'end of Hsp70 in C. gigas, but they did not find a relationship between genetic variability and the expression level of that gene. The analysis of the potential impact of the polymorphic sites of $\mathrm{Hsp} 70$ on gene expression may help to understand the inherent differences in the expression of Hsp70 proteins as well as to clarify the importance that it represents for the suitability of the different species of interest for aquaculture. Thus, genotyping the Hsp70 polymorphic areas, in conjunction with the expression levels and the individual response to the characteristic regional environmental conditions, individuals may be selected to form a broodstock applicable to a breeding program. Individuals with high expression levels of Hsp70 will be better able to address metabolic stress factors as high transcription levels favor a more rapid synthesis, allowing face abrupt changes in the environment or in the presence of pathogens. Valenzuela-Castillo et al. (2015) suggest that individuals of $C$. gigas that express $134,000 \mathrm{Hsp} 70$ transcripts/50 ng of total RNA can be useful in the process of genetic selection for geographical areas of high temperature. Xu et al. (2014) indicated that in Hsp90 of the sea cucumber $A$. japonicus some simple nucleotide polymorphisms are associated to susceptibility and resistance to high- temperature stress and suggest these SNPs as markers in the selection programs of that species.

\section{FINAL COMMENTS}

The comprehensive study of heat-shock proteins is of great importance to both livestock and aquaculture. In this sense, the field of research and the practical application of the results are ample opportunities for development that are just beginning to be discovered. Of particular interest to aquaculture is the knowledge about the impact of the presence of polymorphic sites of Hsp70 on productive traits, such as an association of genotype and cell viability, heat-resistance, and disease-resistance, among others. Furthermore, to determine the feasibility of using Hsp70 as a useful marker in aquaculture, it is necessary to evaluate the presence of cis- and trans-mutations and its relation to the intra-specific variability in the expression of Hsp70 proteins.

Pathogens are a major concern in aquaculture. The evaluation of the role of Hsp70 proteins during the infectious process is needed to understand the role of these proteins in viral replication and pathogenesis development. It will help to understand the response mechanism to pathogens of species of high economic impact such as $C$. gigas and many other bivalve mollusks cultured worldwide.

\section{ACKNOWLEDGMENTS}

The first author received a scholarship from CONACYT.

\section{REFERENCES}

Basiricò, L., Morera, P., Primi, V., Lacetera, N., Nardone, A. \& Bernabucci, U. 2011. Cellular thermotolerance is associated with heat shock protein 70.1 genetic polymorphisms in Holstein lactating cows. Cell Stress and Chaperones, 16: 441-448.

Bernabucci, U., Lacetera, N., Baumgard, L.H., Rhoads, R.P., Ronchi, B. \& Nardone, A. 2010. Metabolic and hormonal acclimation to heat stress in domesticated ruminants. Animal, 4: 1167-1183.

Brokordt, K.B., González, R.C., Farías, W.J. \& Winkler, F.M. 2015. Potential response to selection of HSP70 as a component of innate immunity in the abalone Haliotis rufescens. Plos One, 10(11): e0141959.

Brun, N.T., Bricelj, V.M., Mac Rae, T.H. \& Ross, N.W. 2009. Acquisition of thermotolerance in bay scallops, Argopecten irradians irradians, via differential 
induction of heat shock proteins. Journal of Experimental Marine Biology and Ecology, 371: 77-83.

Calabria, G., Dolgova, O., Rego, C., Castañeda, L.E., Rezende, E.L., Balanyà, J., Pascual, M., Sørensen, J.G., Loeschcke, V. \& Santos, M. 2012. Hsp70 protein levels and thermotolerance in Drosophila subobscura: a reassessment of the thermal co-adaptation hypothesis. Journal of Evolutionary Biology, 25: 691700.

Clark, M.S., Fraser, K.P.P. \& Peck, L.S. 2008. Lack of an Hsp70 heat shock response in two Antarctic marine invertebrates. Polar Biology, 31: 1059-1065.

Dalvi, R.S., Pal, A.K, Tiwari, L.R. \& Baruah, K. 2012. Influence of acclimation temperature on the induction of heat-shock protein 70 in the catfish Horabagrus brachysoma (Günther). Fish Physiology and Biochemistry, 38: 919-927.

Dong, Y.W., Ji, T.T., Meng, X.L., Dong, S.L. \& Sun, W.M. 2010. Difference in thermotolerance between green and red color variants of the Japanese sea cucumber, Apostichopus japonicus Selenka: Hsp70 and heathardening effect. Biological Bulletin, 218: 87-94.

Farcy, E., Voiseux, C., Lebel, J.M. \& Fiévet, B. 2009. Transcriptional expression levels of cell stress marker genes in the Pacific oyster Crassostrea gigas exposed to acute thermal stress. Cell Stress and Chaperones, 14: 371-380.

Franzellitti, S. \& Fabbri, E. 2005. Differential Hsp70 gene expression in the Mediterranean mussel exposed to various stressors. Biochemical and Biophysical Research Communications, 336: 1157-1163.

Gosling, E. 2003. Bivalve mollusks. Biology, ecology, and culture. John Wiley \& Sons, Oxford.

Hamdoun, A.M., Cheney, D.P. \& Cherr, G.N. 2003. Phenotypic plasticity of Hsp70 and Hsp70 gene expression in the Pacific oyster (Crassostrea gigas): implications for thermal limits and induction of thermal tolerance. Biological Bulletin, 205: 160-169.

Hofmann, G.E., Buckley, B.A., Airaksinen, S., Keen, J.E. \& Somero, G.N. 2000. Heat-shock protein expression is absent in the Antarctic fish Trematomus bernacchii (family Nototheniidae). Journal of Experimental Biology, 203: 2331-2339.

Hooper, P.L., Hightower, L.E. \& Hooper, P.L. 2012. Loss of stress response as a consequence of viral infection: implications for disease and therapy. Cell Stress and Chaperones, 17: 647-655.

Jackson, S.A., Uhlinger, K.R. \& Clegg, J.S. 2011. Duration of induced thermal tolerance and tissuespecific expression of $\mathrm{Hsp} / \mathrm{Hsc} 70$ in the eastern oyster, Crassostrea virginica and the Pacific oyster, Crassostrea gigas. Aquaculture, 317: 168-174.

Kang, J.H., Yu, K.H., Park, J.Y., An, C.M., Jun, J.C. \& Lee, S.J. 2011a. Allele-specific PCR genotyping of the
Hsp70 gene polymorphism discriminating the green and red color variants sea cucumber (Apostichopus japonicus). Journal of Genetic and Genomics, 38: 351355.

Kang, J.H., Appleyard, S.A., Elliott, N.G., Jee, Y.J., Lee, J.B., Kang, S.W., Baek, M.K., Han, Y.S., Choi, T.J. \& Lee, Y.S. 2011b. Development of genetic markers in abalone through an SNP database construction. Animal Genetics, 42: 309-315.

Kawabe, S. \& Yokoyama, Y. 2011. Novel isoforms of heat shock transcription factor 1 are induced by hypoxia in the Pacific oyster Crassostrea gigas. Journal of Experimental Zoology Part A Ecology, Genetics, and Physiology, 315: 394-407.

King, M. 2000. Human blood cells: consequences of genetic polymorphisms and variations. Imperial College Press, River Edge.

Konermann, L. 2012. Protein unfolding and denaturants. eLS. John Wiley and Sons, Chichester. doi: 10.1002/9780470015902 a0003004.pub2.

Kresfelder, T.L., Claassen, N. \& Cronjé, M.J. 2006. Hsp70 Induction and Hsp70 Gene polymorphisms as Indicators of acclimatization under hyperthermic conditions. Journal of Thermal Biology, 31: 406-415.

Li, Y., Qin, J.G., Abbott, C.A., Li, X. \& Benkendorff, K. 2007. Synergistic impacts of heat shock and spawning on the physiology and immune health of Crassostrea gigas: an explanation for summer mortality in Pacific oysters. American Journal of Physiology-Regulatory, Integrative and Comparative Physiology, 293: 23532362.

Li, Y., Monroig, O., Zhang, L., Wang, S., Zheng, X., Dick, J.R., You, C. \& Douglas, R.T. 2010. Vertebrate fatty acyl desaturase with $\Delta 4$ activity. Proceedings of the National Academy of Science, USA, 107: 1684016845.

Li, Q., Han, J., Du, F., Ju, Z., Huang, J., Wang, J., Li, R., Wang, C. \& Zhong, J. 2011. Novel SNPs in HSP70A1A gene and the association of polymorphisms with thermotolerance traits and tissue-specific expression in Chinese Holstein cattle. Molecular Biology Reports, 38: 2657-2663.

Lim, D.K.Y., Garg, S., Timmins, M., Zhang, E.S.B., Thomas-Hall, S.R., Schuhmann, H., Li, Y. \& Schenk, P.M. 2012. Isolation and evaluation of oil-producing microalgae from subtropical coastal and brackish waters. Plos One, 7: e40751.

Liu, Y., Gierasch, L.M. \& Bahar, I. 2010. Role of Hsp70 ATPase domain intrinsic dynamics and sequence evolution in enabling its functional interactions with NEFs. PLos Computational Biology, 6: e1000931. 
Liu, Y., Ma, D., Zhao, C., Xiao, Z., Xu, S., Xiao, Y., Wang, Y., Liu, Q. \& Li, J. 2017. The expression pattern of hsp70 plays a critical role in thermal tolerance of marine demersal fish: multilevel responses of Paralichthys olivaceus and its hybrids (P. olivaceus +9 $\times P$. dentatus $\widehat{O})$ to chronic and acute heat stress. Marine and Environmental Research, 129: 386-395.

Malyshev, I. 2013. Immunity, tumors, and aging: the role of Hsp70. Springer Briefs in Biochemistry and Molecular Biology. Springer, London.

Montero-Barrientos, M., Hermosa, R., Cardoza, R.E., Gutiérrez, S., Nicolás, C. \& Monte, E. 2010. Transgenic expression of the Trichoderma harzianum Hsp70 gene increases Arabidopsis resistance to heat and other abiotic stresses. Journal of Plant Physiology, 167: 659-665.

Narum, S.R. \& Campbell, N.R. 2010. Sequence divergence of heat shock genes within and among 3 Oncorhynchids. Journal of Heredity, 101: 107-112.

Nelson, D.L. \& Cox, M.M. 2008. Lehninger principles of biochemistry. W.H. Freeman, Nueva York.

Nollen, E.A. \& Morimoto, R.I. 2002. Chaperoning signaling pathways: molecular chaperones as stresssensing 'heat shock' proteins. Journal of Cell Science, 115: 2809-2816.

Park, H.S., Jeong, W.J., Kim, E., Jung, Y., Lim, J.M., Hwang, M.S., Park, E.J., Ha, D.S. \& Choi, D.W. 2012. Heat shock protein gene family of the Porphyra seriata and enhancement of heat stress tolerance by PsHsp70 in Chlamydomonas. Marine Biotechnology, 14: 332-342.

Pennarossa, G., Maffei, S., Rahman, M.M., Berruti, G., Brevini, T.A.L. \& Gandolfi, F. 2012. Characterization of the constitutive pig ovary heat shock chaperone machinery and its response to acute thermal stress or to seasonal variations. Biology of Reproduction, 87: 19.

Piano, A., Asirelli, C., Caselli, F. \& Fabbri, E. 2002. Hsp70 expression in thermally stressed Ostrea edulis, a commercially important oyster in Europe. Cell Stress and Chaperones, 7: 250-257.

Piano, A., Franzellitti, S., Tinti, F. \& Fabbri, E. 2005. Sequencing and expression pattern of inducible heat shock gene products in the European flat oyster, Ostrea edulis. Gene, 361: 119-126.

Ravaschiere, A., Cutler, C., Edleson, K., Halem, Z., Magun, H., Meckler, F. \& Cox, R. 2017. Quantification of heat shock protein 70 and acetilcholinestirase over a time curse suggests environmental adaptation in a foundational molluscan species. Ecotoxicology and Environmental Safety, 142: 222-229.

Ravaux, J., Toullec, J.Y., Léger, N., López, P., Gaill, F. \& Shillito, B. 2007. First Hsp70 from two hydrothermal vent shrimps, Mirocaris fortunata and Rimicaris exoculata: characterization and sequence analysis. Gene, 386: 162-172.

Richter, K., Haslbeck, M. \& Buchner, J. 2010. The heat shock response: life on the verge of death. Molecular Cell, 40: 253-266.

Roberts, S., Goetz, G., White, S. \& Goetz, F. 2009. Analysis of genes isolated from plated hemocytes of the Pacific oyster, Crassostrea gigas. Marine Biotechnology, 11: 24-44.

Roberts, R.J., Agius, C., Saliba, C., Bossier, P. \& Sung, Y.Y. 2010. Heat shock proteins (chaperones) in fish and shellfish and their potential role in relation to fish health: a review. Journal of Fish Diseases, 33: 789801.

Samain, J.F. 2011. Review and perspectives of physiological mechanisms underlying geneticallybased resistance of the Pacific oyster Crassostrea gigas to summer mortality. Aquatic Living Resources, 24: $227-236$.

Spriggs, K.A., Bushell, M. \& Willis, A.E. 2010. Translational regulation of gene expression during conditions of cell stress. Molecular Cell, 40: 228-237.

Sung, Y.Y., Mac Rae, T.H., Sorgeloos, P. \& Bossier, P. 2011. Stress response for disease control in aquaculture. Reviews in Aquaculture, 3: 120-137.

Swynghedauw, B. 1998. Molecular cardiology for the cardiologist. Kluwer Academic Publishers, Boston.

Thompson, E.L., Taylor, D.A., Nair, S.V., Birch, G., Coleman, R. \& Raftos, D.A. 2012. Optimal acclimation periods for oysters in laboratory-based experiments. Journal of Molluscan Studies, 78: 304307.

Tine, M., Bonhomme, F., McKenzie, D.J. \& Durand, J.-D. 2010. Differential expression of the heat-shock protein Hsp70 in natural populations of the tilapia, Sarotherodon melanotheron, acclimatized to a range of environmental salinities. BMC Ecology, 10: 1-8.

Tissieres, A., Mitchell, H.K. \& Tracy, U.M. 1974. Protein synthesis in salivary glands of Drosophila melanogaster: relation to chromosome puffs. Journal of Molecular Biology, 84: 389-398.

Tomanek, L. \& Somero, G.N. 2002. Interspecific- and acclimation-induced variation in levels of heat-shock proteins congeneric marine snails (genus Tegula): implications for regulation of hsp gene expression. Journal of Experimental Biology, 205: 677-685.

Valenzuela-Castillo, A., Sánchez-Paz, A., CastroLongoria, R., López-Torres, M.A. \& Grijalva-Chon, J.M. 2015. Seasonal changes in gene expression and polymorphism of Hsp70 in cultivated oysters (Crassostrea gigas) at extreme temperatures. Marine and Environmental Research, 110: 25-32. 
Valenzuela-Muñoz, V., Araya-Garay, J.M. \& GallardoEscárate, C. 2013. SNP discovery and high-resolution melting analysis from massive transcriptome sequencing in the California red abalone Haliotis rufescens. Marine Genomics, 10: 11-16.

Wang, B., Li F., Dong, B., Zhang, X., Zhang, C. \& Xiang, J. 2006. Discovery of the genes in response to white spot syndrome virus (WSSV) infection in Fenneropenaeus chinensis through cDNA microarray. Marine Biotechnology, 8: 491-500.

Wei, T., Sun, Y., Shi, G., Wang, R. \& Xu, T. 2012. Characterization and SNP variation analysis of a Hsp70 gene from miiuy croaker and its expression as related to bacterial challenge and heat shock. Fish and Shellfish Immunology, 33: 632-640.

Wenne, R. 2018. Single nucleotide polymorphism markers with applications in aquaculture and assessment of its impacts on natural populations. Aquatic Living Resources, 31: 2 pp.

Willmund, F., Alamo, M. \& Pechmann, S. 2013. The cotranslational function of ribosome-associated Hsp70 in eukaryotic protein homeostasis. Cell, 152: 196-209.

Witt, S.N. 2010. Hsp70 molecular chaperones and Parkinson's disease. Biopolymers, 93: 218-228.

Received: 29 June 2017; Accepted: 5 September 2018
Wojtasik, B. \& Wiśnik, D.K. 2012. Temperature shock tolerance and heat shock proteins in Arctic freshwater ostracod Candona rectangulata- preliminary results. Polish Polar Research, 33: 199-206.

Xu, D., Sun, L., Liu, S., Zhang, L. \& Yang, H. 2014. Polymorphisms of heat shock protein 90 (Hsp90) in the sea cucumber Apostichopus japonicas and their association with heat-resistance. Fish and Shellfish Immunology, 41: 428-436.

Yue, X., Liu, B., Sun, L. \& Tang, B. 2011. Cloning and characterization of a hsp70 gene from Asiatic hard clam Meretrix meretrix which is involved in the immune response against bacterial infection. Fish and Shellfish Immunology, 3: 791-799.

Zerebecki, R.A. \& Sorte, C.J.B. 2011. Temperature tolerance and stress proteins as mechanisms of invasive species success. Plos One, 6: e14806.

Zizzari, Z.V. \& Ellers, J. 2011. Effects of exposure to short-term heat stress on male reproductive fitness in a soil arthropod. Journal of Insect Physiology, 57: 421426. 